\title{
Del valor intrínseco de la naturaleza*
}

\author{
Fernando Arribas Herguedas \\ Universidad Rey Juan Carlos
}

Resumen. La ética ecológica considera la noción de «valor intrínseco» como un requisito necesario para establecer deberes morales hacia el mundo no humano. En este artículo, sin embargo, se sostiene que las concepciones ecocéntricas del valor intrínseco se traducen generalmente en alguna clase de naturalismo y que el antropocentrismo ético es inevitable. En segundo lugar, se muestra cómo la atribución de valor intrínseco obstaculiza la tarea de jerarquizar deberes ecológicos. Por último, se defiende que las apelaciones al valor intrínseco son traducibles a concepciones «ilustradas» del valor instrumental que asuman la incertidumbre derivada de la ciencia ecológica y la inconmensurabilidad de valores que subyace a los problemas ambientales. Con ello se afrontan la mayoría de preocupaciones biocéntricas, por cuanto el valor intrínseco de la vida defendido por el biocentrismo puede interpretarse, desde una posición antropocéntrica, como «principio de reversión de la carga de la prueba».

Palabras clave: Ética ecológica, antropocentrismo, biocentrismo.

\section{I}

«Estamos abismados en un universo pleonástico, en el que las interrogaciones y las réplicas se equivalen.» Émile Cioran ${ }^{1}$
ABSTRACT. Environmental ethics considers the notion of 'intrinsic value' a necessary requirement to establish moral duties toward the non-human world. However, it is held here that the ecocentric conceptions of intrinsic value usually results in some kind of naturalism and that moral anthropocentrism is inevitable. Secondly, it will be shown how the conferring of intrinsic value hinders the work of arranging ecological duties in order of importance. Finally, it will be defended that appeals to intrinsic value are translatable to 'enlightened' conceptions of instrumental value which undertake the ecological uncertainty and the underlying incommensurability of values at environmental problems. Thus it can be faced up to most of biocentric concerns, in that intrinsic value of life that biocentrism defends may be interpreted, from an anthropocentric outlook, as a «reversion of the burden of proof principle».

Key words: Ecological ethics, anthropocentrism, biocentrism.

Durante los últimos años, la ética ecológica ha mantenido que para hacernos cargo de los problemas ambientales hemos de edificar una axiología o teoría del valor de mayor alcance que la proporcionada por las éticas tradicionales. 
Con tal fin, el «valor intrínseco» de la naturaleza se ha convertido en la premisa por excelencia de su discurso. Pero las apelaciones al valor intrínseco se han entremezclado con la tarea de dar razones para fundamentar deberes hacia el mundo no humano y con los ataques contra el «antropocentrismo» inherente a la «ética clásica» o «tradicional». ${ }^{2} \mathrm{El}$ antropocentrismo es, según la ética ecológica, una visión filosófica dualista, anclada en el pensamiento y la religión dominantes en la cultura occidental, que sólo considera merecedores de valor intrínseco a los seres humanos y sus intereses. Su predominio secular explicaría que el mundo carezca de «consideración moral» por nuestra parte. ${ }^{3}$ Esta crítica del antropocentrismo caracteriza gran parte de los intentos de edificar una «nueva ética» que, animada por los importantes avances de la ecología científica, se haga cargo de la actual crisis ambiental. ${ }^{4}$

El discurso de esta «nueva ética» ha enredado las derivaciones ontológicas de la ecología con la tarea de fundamentación ética, buscando los rasgos «objetivos» definitivos que permitan justificar la ampliación del ámbito de la moralidad. Así, el utilitarismo reconoce que todas las criaturas susceptibles de experimentar sufrimiento deberían ser dignas de consideración moral, pero esto deja insatisfechos a muchos autores, ya que establece lo que Robin Attfield denomina «privilegio de lo sintiente» al despojar de relevancia moral a seres cuya capacidad de experimentar placer o dolor dista de estar claramente demostrada (como es el caso de las encinas centenarias o las bacterias). ${ }^{5}$ De ahí que el biocentrismo postule la «condición de estar vivo» como «criterio razonable y no arbitrario» de consideración moral. ${ }^{6}$ Es importante advertir que para el biocentrismo sólo los seres humanos pueden ser «agentes morales» (es decir, sujetos de obligaciones) mientras que los seres vivos no humanos (y los humanos con sus capacidades de juicio seriamente afectadas) serían contemplados como «pacientes morales» (objeto de nuestros deberes). Pero bajo el punto de vista biocéntrico las montañas o los cauces de los ríos aún poseerían un valor subordinado al de los organismos vivos. Dando un paso más, el ecocentrismo también considera portadores de valor intrínseco a los ecosistemas e incluso a la biosfera en su totalidad. Es la clase de valor que Holmes Rolston III denomina «valor sistémico». ${ }^{7}$

Lo que comparten todas estas visiones, frente a lo que genéricamente denominan «antropocentrismo», es la afirmación de que el mundo no humano o partes de él «importan» más allá de su posible empleo como medio para fines humanos ulteriores y que esa importancia deriva del «valor intrínseco» («valor no instrumental» o «valor como fin en sí») que es «descubierto» o «desvelado» por la ecología científica. Pero este sentido habitual de la expresión «valor intrínseco» se entremezcla a menudo con una noción metaética de «valor objetivo» o «valor que un objeto posee independientemente de las valoraciones de los que valoran». 8 Una buena muestra de esta anfibología la ofrece el ecologista «profundo» Fritjof Capra:

La ecología superficial es antropocéntrica, es decir, está centrada en el ser humano. Ve a éste por encima o aparte de la naturale$\mathrm{za}$, como fuente de todo valor, y le da a aquélla un valor únicamente instrumental, «de uso». La ecología profunda no separa a los humanos -ni a ninguna otra cosa- del entorno natural. Ve el mundo, no como una colección de objetos aislados, sino como una red de fenómenos fundamentalmente interconectados e interdependientes. La ecología profunda reconoce el valor intrínseco de todos 
los seres vivos y ve a los humanos como una mera hebra de la trama de la vida. ${ }^{9}$

Comprobamos aquí cómo el ecocentrismo tiende a enmarañar los niveles ontológico y ético del discurso. Así, «ver al ser humano por encima o aparte de la naturaleza» es una proposición ontológica propia de un antropocentrismo «fuerte» basado en un dualismo radical que explica por qué la naturaleza posee «un valor únicamente instrumental». La expresión «valor intrínseco» equivale aquí a un mismo tiempo a la noción metaética de «valor objetivo» (noción que no dice nada acerca de nuestros deberes morales) y a la noción de «valor como fin en sí» (que tiene claras implicaciones éticas, por cuanto algo que posee valor como fin en sí no debe ser empleado como medio para otros fines). En principio, debería quedar claro el sentido de la expresión «valor objetivo» cuando, por ejemplo, nos referimos a aquello que satisface una necesidad biológica determinada. Así, es innegable que el agua posee valor objetivo para la conservación de la vida «con independencia de las valoraciones de los que valoran» o de su presencia. Pero este sentido del término «valor» y de la acción de valorar, que no es privativo de la especie humana, no tiene nada que ver con la noción de valor intrínseco en sentido moral; pues puedo reconocer el valor objetivo del agua para la vida de alguien pero aun así negarme a proporcionársela afirmando no sentirme concernido por deber alguno que me obligue a hacerlo. Reconocer el valor objetivo no es suficiente para prescribir deberes morales. Hacen falta premisas adicionales para afirmar el valor intrínseco de algo y tratarlo como un fin en sí. ${ }^{10}$

Con todo, muchos filósofos de la ecología creen que «descubrir» el valor objetivo de seres o ecosistemas es condición suficiente para afirmar su valor no instrumental o valor como fin en sí, deslizándose hacia alguna variante de naturalismo ético. Ello se debe a que la cruzada antiantropocéntrica exige combatir toda forma de subjetivismo. Pero es erróneo identificar necesariamente éste con posiciones éticas instrumentalistas, del mismo modo que, como ya he dicho, el reconocimiento de propiedades objetivas no trae de suyo la obligación moral de respetarlas. ${ }^{11}$ Es indudable que la ecología científica afianza una ontología naturalista que subraya las continuidades biológicas entre el ser humano y el mundo. La premisa metaética de la interdependencia biótica tiene una importancia decisiva para nuestra forma de actuar en el futuro, por cuanto revela incertidumbres esenciales que hemos de tener en cuenta a la hora de fundamentar deberes morales hacia nuestros semejantes y hacia el mundo no humano. Pero el «nuevo paradigma» debe contemplarse como un paso adelante en el ideal ilustrado del conocimiento racional, ya que apuesta claramente por la fundamentación intersubjetiva de la «verdad» y la transdisciplinariedad científica. Así pues, lo que en ningún caso cabría derivar de él es un fundamento absoluto para los deberes morales, algo a lo que, en definitiva, aspira el naturalismo ético (ejemplificado por el darwinismo de Holmes Rolston III, a pesar de sus reiteradas recomendaciones de cautela ante la falacia naturalista). Así, tras afirmar que «el tiempo evolutivo tiene una dirección ascendente», Rolston sostiene que «el debe no se deriva tanto de un es, sino que más bien se descubre simultáneamente con el $e s »{ }^{12}$ En sus ataques contra el antropocentrismo, los ecocentristas como Rolston confunden dos dimensiones del término, sin advertir que su relación mutua es meramente contingente. Es cierto que la ontología dualista antropocéntrica se ve seriamente cuestionada por la ecología científica que viene a recordarnos que 
somos tan sólo un sofisticado producto biológico de la inagotable capacidad autopoiética de Gaia. Sin embargo, el rechazo de la ontología antropocéntrica no nos permite abandonar el «antropocentrismo ético» al que estamos inevitablemente encadenados, como nos recuerda Javier Muguerza:

[L]a ética no puede ser sino antropocéntri$c a$. El antropocentrismo ético no excluye la heterodirección de la preocupación moral más allá de los confines de la especie humana. Y una ética antropocéntrica podría incluso ser hecha compatible con una ontología cosmocéntrica. Pero la idea de una «ética cosmocéntrica» no ofrece, al menos hoy por hoy, alternativa alguna al antropocentrismo ético, pues ni el cosmos en su conjunto ni ninguno de sus habitantes no-humanos conocidos [...] son, ni lo podrían ser, sujetos morales. ${ }^{13}$

Lo que Muguerza denomina «heterodirección de la preocupación moral más allá de los confines de la especie humana» equivaldría a la pretendida ampliación de la esfera de consideración moral que biocentristas como Goodpaster o Attfield defienden, aunque sin afirmar que todo lo que posee «una naturaleza propia» adquiere de suyo «valor intrínseco». ${ }^{14}$ Es decir, Muguerza considera que sólo los seres humanos somos «agentes» morales pero podemos (y seguramente debemos) extender el alcance de nuestros deberes reconociendo el status de «pacientes» morales a los seres no humanos. Por lo que podemos aventurar ya que para el viaje de la consideración moral ecológica quizá no sean necesarias las alforjas del concepto de valor intrínseco.

\section{II}

Los seres humanos somos los únicos seres «constitutivamente morales» $\mathrm{y}$, por tanto, la única «fuente» conocida de valor moral. 15 Por tanto, entender el valor intrínseco como «valor objetivo» sólo aporta confusión en la tarea de fundamentación ética, pues el valor moral no es una propiedad objetiva sino algo que atribuimos los seres humanos a otros seres u objetos. Sostener lo contrario significa abrazar alguna variante de naturalismo ético edificada sobre los tambaleantes cimientos de una obsesión antiantropocéntrica. Esto no significa que las premisas metaéticas carezcan por completo de relevancia para la ética; pues, en efecto, de continuo apoyamos nuestros juicios éticos con apelaciones a los hechos. Pero otra cosa es que derivemos obligaciones morales desde proposiciones fácticas. Cuando advierto a alguien diciendo «no debes fumar aquí dentro», me apoyo en estudios científicos que muestran cómo los fumadores «pasivos» también contraen cáncer. Con ello no cometo la falacia naturalista (si lo hiciera, casi todos los juicios éticos resultarían inconcebibles). Incurro en ella, sin embargo, cuando digo: «puesto que es nocivo fumar, nadie debe fumar»; es decir, cuando deduzco el deber del ser. La independencia mutua entre ambas esferas queda clara cuando, valorando intrínsecamente la libertad individual (aunque sea para dañarse a uno mismo), antepongo ésta al hecho objetivo de que el tabaco mata y formulo mi juicio del siguiente modo: «puesto que es nocivo fumar, nadie debe fumar $s i$ con ello causa un perjuicio a terceros». Aquí vemos cómo una proposición fáctica condiciona mi juicio ético -hoy sabemos que el tabaco mata, como también sabemos que el «efecto invernadero» tiene algo que ver con nuestra actividad económica depredadora- pero no se antepone lógicamente a él. Del mismo modo, puedo aceptar como un hecho objetivo que mi despilfarro de energía causa perjuicios graves al planeta pero continuar tranquilamente conduciendo 
un potente automóvil. En suma, la interdependencia biótica puede condicionar nuestra forma de relacionarnos con el mundo, pero no dicta prescripciones que nos permitan evitar la tarea de aportar razones para establecer deberes morales.

Una vez que captamos la inconsistencia de las concepciones ecocéntricas y rechazamos las tentaciones naturalistas de fusionar el valor intrínseco y el valor objetivo, hemos de plantear otra cuestión. Se trata de comprobar si la atribución de valor intrínseco, entendido como «valor no instrumental» $\mathrm{o}$ «valor como fin en sí», es condición necesaria para otorgar consideración moral. Este sentido de la noción de valor intrínseco se ha aplicado generalmente a los seres racionales y sus intereses vitales. La versión más conocida del principio de no instrumentalización es la formulación kantiana del imperativo categórico recogida en la Fundamentación de la metafísica de las costumbres: "obra de tal modo que te relaciones con la humanidad, tanto en tu persona como en la de cualquier otro, siempre como un fin, y nunca sólo como un medio». ${ }^{16}$ Este manifiesto antropocentrismo explica el rechazo de la ética ecológica hacia Kant. A ello se añade el relativo desdén que el filósofo alemán mostraba hacia los animales afirmando explícitamente que «existen únicamente en tanto que medios» y que «no tenemos por lo tanto ningún deber para con ellos de modo inmediato». ${ }^{17}$ Kant consideraba los deberes hacia el mundo no humano como «deberes indirectos» hacia la humanidad y no contemplaba la posibilidad de otorgarle valor intrínseco alguno.

Pero eso no significa que los animales no merecieran ninguna consideración moral para Kant. De hecho, en su opinión, «el hombre ha de ejercitar su compasión con los animales, pues aquel que se comporta cruelmente con ellos posee asimismo un corazón endurecido para con sus congéneres. Se puede, pues, conocer el corazón humano a partir de su relación con los animales».18 Vemos cómo los animales son medios para fines humanos pero, sin embargo, merecen un trato incruento. Lo que pretendo señalar, tras afirmar la inevitabilidad del antropocentrismo ético, es que atribuir valor intrínseco a algo o alguien es una condición suficiente para otorgarle consideración moral, pero quizá no sea una condición necesaria en todos los casos. En otras palabras, la cuestión es si se puede reconocer el status de paciente moral hacia algo o alguien sin postular su valor intrínseco. De hecho, una ética que se haga cargo de la cuestión ecológica no tendrá más remedio que recurrir a esta estrategia, debido a dos razones que ponen en dificultades la posibilidad de atribuir valor intrínseco al mundo no humano. En primer lugar, la incertidumbre aparejada a la mayoría de las contribuciones de la ecología científica, que ponen de manifiesto la complejidad de la interdependencia biótica y los límites de la razón humana para dominar la naturaleza, transforma de continuo, y a veces inesperadamente, nuestros criterios de valor. En segundo lugar, la instrumentalización inherente a la interdependencia biótica -sin muerte no puede continuar habiendo vida - convierte el empleo de la idea de valor intrínseco en un obstáculo para la prescripción de deberes morales, pues ésta exige una ordenación jerárquica de las entidades que poseen dicho valor.

Como ha mostrado Tom Regan, las teorías del valor intrínseco «en términos de fines en sí mismos» no pueden jerarquizar los diferentes valores intrínsecos sin convertir aquellos que quedan supeditados en valores instrumentales, lo que las condena a la superficialidad. ${ }^{19}$ Ello se debe a que «el valor intrínseco aplicado 
a los individuos en tanto que fines en sí mismos es un concepto categórico; es decir, $o$ los individuos existen como fines en sí mismos $o$ no, y entre los que sí existen como fines en sí mismos nadie tiene esta categoría en mayor grado que otro». ${ }^{20}$ Regan muestra cómo las teorías ecológicas del valor intrínseco se apoyan inadvertidamente en concepciones del valor instrumental cuando tratan de jerarquizar los diferentes intereses en juego. Invocar el valor intrínseco en una teoría de «fines en sí mismos» no satisface las exigencias de economía conceptual.

\section{III}

El carácter superfluo y problemático del empleo de la noción de valor intrínseco se advierte incluso en teorías más desarrolladas como la ética biocéntrica de Robin Attfield. Apartándose de la tentación naturalista, Attfield distingue el «antropocentrismo tradicional», caracterizado por su prometeísmo, del «antropocentrismo epistémológico» que se hace cargo de la inevitabilidad del origen subjetivo del valor moral, sin dejar de aspirar a establecer una «ética cosmopolita» que estipule principios universalizables. ${ }^{21}$ La reflexión de Attfield parte de la «objetividad» ecológica de ciertas necesidades o rasgos específicos de los organismos vivos, ya que todos ellos necesitan realizar una serie de funciones biológicas básicas para florecer y desarrollar sus capacidades. Este elemento objetivo sirve para articular una concepción biocéntrica que otorga relevancia moral a todos los seres vivos considerándolos «pacientes morales». Ahora bien, Attfield señala que de ahí no debe derivarse un igualitarismo biocéntrico. La relevancia o consideración moral ha de distinguirse de la «importancia moral». ${ }^{22} \mathrm{La}$ idea de importancia o significación moral asume que la posesión de necesidades específicas «objetivas» por parte de los distintos seres vivos no trae de suyo la afirmación ética de su igual valor, del mismo modo que la confirmación de que el humo del tabaco produce cáncer no nos legitima para perseguir a los fumadores (y sí lo hace la vulneración del derecho de los no fumadores a respirar un aire limpio si así lo desean). Necesitamos, como ya he dicho, una premisa adicional para dar ese paso.

Attfield hace suya, pues, una visión objetivista «débil» del valor: allí donde podemos establecer necesidades, capacidades y una idea de «bien en sí» basada en su florecimiento, podemos también apoyar ciertos juicios éticos, aunque en ningún caso derivarlos. El escalón siguiente para una ética ecológica es establecer un criterio razonable para jerarquizar los diferentes intereses vitales en conflicto sin sacrificar el pluralismo axiológico que caracteriza a las sociedades contemporáneas. En realidad, ambos retos no son privativos de la ética ecológica, sino que han de ser afrontados por cualquier teoría que no quiera convertirse en una «doctrina comprehensiva», en la terminología de John Rawls. ${ }^{23}$ Pero en este punto la propuesta de Attfield sucumbe innecesariamente a la tentación de disolver los problemas con una concepción del valor intrínseco. Así, afirma que la significación o importancia moral de los intereses de un ser vivo «depende de su valor intrínseco o de su contribución a tal valor» y que el valor intrínseco es «una razón para la acción independiente o no derivada y basada solamente en la naturaleza de lo que tiene este valor». Esta definición solamente distingue las acciones que no están motivadas por la consecución de un fin ulterior a la acción misma de aquellas otras que sí lo estarían; es decir, hace equivaler el valor intrínseco al valor no instrumental. Lo que es necesario saber $-\mathrm{y}$ se supone que 
Attfield introduce la noción de valor intrínseco con ese propósito- es cuándo y hacia qué o quién se exige de nosotros que actuemos de tal modo, es decir, qué criterio moral substantivo aplicar para determinar qué intereses vitales no son en ningún caso sacrificables para fines ulteriores. Attfield da un paso en esta dirección haciendo descansar el valor intrínseco «en el bien o el bienestar de los portadores de la relevancia moral», bien que a su vez consiste en «el desarrollo de las capacidades esenciales de su especie», teniendo en cuenta que «las capacidades más complejas y desarrolladas (tales como la autonomía) preceden a las más simples y menos sofisticadas, pero sólo cuando ambas estén en juego». ${ }^{24}$ Esto último supone que los seres pertenecientes a una «especie sofisticada» no poseerán una «prioridad automática» sólo por el hecho de estar dotados de capacidades más «complejas y desarrolladas».

Estas definiciones resultan decepcionantemente circulares, puesto que si la significación moral de los intereses de un organismo «depende de su valor intrínseco o de su contribución a tal valor», tendremos que aportar un criterio substantivo para establecer éste y después derivar de él la significación moral de los diferentes organismos. Pero Attfield regresa al punto de partida -el «igualitarismo biocéntrico»- cuando equipara el valor intrínseco con «el bien o el bienestar de los portadores de la relevancia moral»; pues todo organismo -incluidos los virus peligrosos- posee un «bien propio» al que tiende de suyo. El atisbo de criterio de significación moral que representa la preferencia por los intereses de los seres más complejos en caso de conflicto es una buena muestra de los problemas que genera la idea de valor intrínseco cuando tratamos de aplicarla al mundo no humano. Porque Attfield, al establecer que en caso de conflicto entre los intereses de dos o más especies han de primar los de la más «sofisticada», está sacrificando el valor intrínseco de la especie menos sofisticada y convirtiéndolo en valor instrumental. La idea de valor intrínseco es en este contexto, como apuntaba Regan, innecesaria. Nuestras decisiones acerca de lo que debe ser respetado han de contrapesar intereses en circunstancias específicas $\mathrm{y}$, según el consecuencialismo biocéntrico de Attfield, prever los resultados. Este «cálculo» de consecuencias posibles es inconcebible sin tener en cuenta las relaciones de «instrumentalidad» entre los diferentes organismos vivos. Si tras dicho cálculo determinamos que infligir daño «gratuito»a animales y plantas es rechazable moralmente, entonces no nos hemos apartado tanto como creemos de la noción de valor instrumental que subyace a la idea de los «deberes indirectos» estipulados deontológicamente por Kant.

La teoría de Attfield tiene el mérito de combinar acertadamente una perspectiva consecuencialista imprescindible para afrontar los problemas ecológicos -puesto que la actividad humana tiene efectos imprevisibles sobre el entorno y los mandatos incondicionales pueden volverse en contra de nuestras bienintencionadas acciones - con la exigencia incondicional de dar prioridad a los intereses humanos justificados. Pero para tal fin no es necesaria la idea de valor intrínseco, pues ésta es reductible a diferentes concepciones del valor instrumental. La prueba de ello es que cuando Attfield afirma el valor como fin en sí de los organismos no humanos e inmediatamente, para evitar el «igualitarismo biocéntrico», sostiene que la significación moral dependerá del grado de complejidad de los intereses que entran en conflicto, en cierto modo está volviendo a situar al ser humano en la «cúspide de la 
creación». ${ }^{25} \mathrm{Si}$ los intereses respectivos de los humanos y de otras especies no entran en conflicto, entonces es evidente que, como afirmaba Kant, no debemos causar daño: pues al infligir sufrimiento gratuito causamos, indirectamente, un daño a la humanidad (presente y futura). Así pues, reconocer deberes hacia el mundo no humano no implica reconocer su valor intrínseco, del mismo modo que establecer criterios de significación moral (tarea ineludible, pues el mundo conocido es una sucesión continua de instrumentalización de unos seres por otros) exige de nosotros favorecer concepciones «ilustradas» del valor instrumental. De otro modo no podríamos comer pimientos y proteger encinas centenarias al mismo tiempo, cosas ambas necesarias para el desarrollo de nuestras capacidades, pero también para el desarrollo de las capacidades de otros organismos. ${ }^{26}$ Lo importante aquí es advertir que las razones para comer pimientos y proteger encinas pueden descansar en supuestos puramente instrumentales sin que se resienta el «bien propio» al que tienden unos y otras (aunque todo apunta a que los pimientos saldrán peor parados con independencia de que adoptemos una posición biocéntrica o antropocéntrica). Lo que está en juego es justificar qué intereses humanos es deseable perseguir y qué concepciones del valor (instrumental) resultan inadmisibles a la luz de tales intereses. Hemos de precisar ahora, por tanto, de qué modo podría entenderse el «valor instrumental» sin que, como sucede habitualmente en el discurso de la ética ecológica, se identifique con actitudes irrespetuosas hacia el mundo no humano.

\section{IV}

«Pues lo que acaso haya que hacer con las tensiones filosóficas no es tanto tratar de apaciguarlas cuanto exacerbarlas, hasta conseguir descifrar en ellas el indicio que a no dudarlo son de nuestra condición humana». Javier Muguerza 27

Si seguimos el consejo de Muguerza, no habremos de zanjar las controversias de la ética ecológica apelando a una única idea de valor intrínseco, aunque tampoco desoír a aquellos que tratan de justificarlas, pues ambas serían formas igualmente nocivas de eliminar las «tensiones filosóficas». Aquí he pretendido «exacerbar» la tensión entre aquellos que consideran imprescindible la noción de valor intrínseco para prescribir deberes hacia la naturaleza y aquellos que, como yo, la contemplan como un innecesario pleonasmo. He afirmado en consecuencia que la significación moral del mundo no puede fundarse en una concepción del valor intrínseco debido a las dificultades para establecer criterios de instrumentalización «razonable» ante los problemas ecológicos. Captar la complejidad inherente a las relaciones entre organismos y ecosistemas no nos proporciona un conocimiento exhaustivo del mundo ni, por tanto, una aprehensión directa del valor intrínseco de la naturaleza. La idea importante aquí es que los criterios para establecer la jerarquía de significación moral en el mundo no humano -que son los realmente decisivos - están sujetos a cambios profundos y acelerados como consecuencia, precisamente, de las intervenciones humanas en el medio, lo que cuestiona de continuo nuestras concepciones más arraigadas del valor instrumental. En otros términos, el problema fundamental que debe afrontar una ética ecológica es la inconmensurabilidad entre nuestras concepciones del valor. No cabe hablar entonces de una «nueva ética», aunque quizá cabría hacerlo de una ética que asuma la derivación metaética más importante de la ecología científica: la incertidumbre epistemológica. 
A mi juicio, esta incertidumbre viene a enterrar las ilusiones de encontrar un fundamento absoluto para interpretar unívocamente el «sentido» moral del mundo, ya que nos deja completamente solos ante la responsabilidad de preservarlo o destruirlo. Gran parte del discurso de la ética ecológica ha interpretado esta soledad filosófica de una forma errónea, cayendo una vez más en la tentación de «leer» en el libro de la naturaleza. Por esta razón, la lectura de muchos textos de ética ecológica nos produce la sensación de estar dando un espectacular rodeo para llegar, finalmente, a prescripciones morales que bien podrían alcanzarse en términos de intereses humanos.

Esto se capta especialmente cuando contemplamos la ética ecológica desde el punto de vista de su potencial político. A la hora de articular institucionalmente deberes hacia el mundo no humano observamos que el cultivo del pluralismo axiológico, que es un valor fundamental de las sociedades contemporáneas, exige integrar tales deberes como parte de una «vida buena», como cuestiones de justicia social o como obligaciones hacia las generaciones futuras. ${ }^{28} \mathrm{En}$ otras palabras: la neutralidad entre las diferentes concepciones del bien, como valor central de ese pluralismo, adquiere una dimensión diferente ante los problemas ecológicos, pues éstos transforman inevitablemente nuestras ideas establecidas el bien y de la justicia. Si contemplamos la cuestión ecológica en esta dimensión más «política», la tarea del filósofo no habrá de ser ya la de «exacerbar» las tensiones sino, en cierto modo, «apaciguarlas», al menos entre los filósofos de la ecología, quienes recuerdan con demasiada frecuencia a las liebres que discutían acerca del pedigrí de los perros que hacia ellas se lanzaban. Como decía John Rawls, una de las tareas fundamentales de la filosofía política, que él denominaba su «papel práctico», ha de ser «fijar la atención en las cuestiones profundamente disputadas y ver si, pese a las apariencias, puede descubrirse alguna base subyacente de acuerdo filosófico y moral». De no ser así, como parece suceder entre los defensores y los detractores del valor intrínseco de la naturaleza, Rawls creía en la filosofía política como un medio para que «al menos pueda limitarse la divergencia de opinión filosófica y moral que está en la raíz de las políticas divisivas, de tal modo que todavía pueda mantenerse la cooperación social entre ciudadanos sobre la base del respeto mutuo». ${ }^{29}$ Este espíritu pragmático nutre discursos ecológicos como la «hipótesis de la convergencia» de Bryan Norton, quien está convencido de que el monismo ético que ha perseguido gran parte de la filosofía ecológica, con el convencimiento de que ello serviría para dar fuerza al movimiento verde, se ha revelado como una estrategia errónea. ${ }^{30}$ Norton muestra cómo las propuestas políticas de las distintas corrientes y movimientos de la familia ecologista no difieren tanto como dan a entender sus fracturas teóricas. De ahî que muchas de las estrategias de acción política puedan justificarse apelando a intereses humanos y que carezca de sentido la distinción entre ecología «profunda» y «superficial». Los intentos de encontrar una noción última de valor intrínseco que actúe como un «talismán moral» y que descanse en «verdades autoevidentes» se inscriben en esta errada concepción de la ética ecológica. ${ }^{31}$

Estoy básicamente de acuerdo con Norton en la posibilidad de justificar la mayoría de propuestas ambientales apelando solamente a «intereses humanos». Como ya he dicho, esto supone hacerse cargo de la inconmensurabilidad entre las diferentes concepciones humanas del valor $\mathrm{y}$, por tanto, establecer prioridades entre necesidades y deseos. Plantear de 
esta forma la cuestión ecológica permite crear un espacio amplio de entendimiento entre las posiciones de antropocentrismo ético ecológicamente «ilustradas»y el biocentrismo moderado. La aportación decisiva de este último, como hemos comprobado en el caso de las propuestas de Attfield y Goodpaster, es situar la vida y su conservación como principio de consideración moral. Desde mi punto de vista, este principio posee, sin necesidad de vincularse con una esquiva noción de «valor intrínseco», un potencial evidente en forma de lo que denomino «principio de reversión de la carga de la prueba». Este principio operaría como el fundamento ético de la estipulación de derechos ambientales para los seres humanos y como inspirador de la legislación ambiental. El principio descansa, fundamentalmente, en un criterio prudencial que establece que aquellos que emprendan intervenciones en el medio han de mostrar por adelantado que tales intervenciones proporcionan alguna clase de valor superior al que perdemos con ellas. Este principio de responsabilidad por la destrucción ambiental tendría que hacer frente a los problemas derivados de la inconmensurabilidad $\mathrm{y}$, por tanto, a los problemas de la traducción en términos de valor instrumental de diferentes clases. Allí donde el valor intrínseco -reservado a los seres humanos y sus derechos, incluidos los ambientales- se ponga en peligro, ningún valor instrumental, por elevado que sea, podrá justificarse. Pero, además, la dificultad de hacer conmensurables el valor instrumental de, por ejemplo, la conservación de determinadas especies y la construcción de infraestructuras viarias, dejaría de recaer sobre aquellos que se oponen a las intervenciones. En la actualidad, éstos tienen que demostrar que la conservación aporta más valor que la intervención. Pero esa demostración resulta imposible porque los términos en los que se mide socialmente el valor son siempre desfavorables para los conservacionistas, sobre todo porque no hay criterios sociales adecuados para «medir» la irreversibilidad ecológica hasta que no se ha producido. De este modo, las políticas de hechos consumados, como el urbanismo costero en nuestro país, no encuentran obstáculos en su camino, puesto que la demostración de la irreversibilidad suele llegar años después.

La cuestión fundamental para una ética ecológica no es, por tanto, encontrar una formulación adecuada del «valor intrínseco» de la naturaleza. El verdadero problema es que las articulaciones institucionales de las políticas ambientales no favorecen realmente el pluralismo axiológico porque dejan fuera una inmensa gama de concepciones del valor instrumental respetuosas con la naturaleza al imponérseles la carga de la prueba cuando defienden la preservación de especies o hábitats. Por ello es de la mayor importancia que entendamos el valor instrumental como una clase muy amplia de valor que no puede expresarse a través de un único lenguaje. Generalmente, la literatura ecológica se refiere peyorativamente al valor instrumental como el valor que algo posee «para fines humanos», como si la obtención de satisfacción o beneficio a través de nuestra relación con la naturaleza pusiera ésta en peligro. Hay aquí un rigorismo ético mal entendido que viene a equiparar la explotación exhaustiva de la naturaleza como un mero «recurso» $\mathrm{O}$ «materia prima» con muchas otras acciones encaminadas a protegerla, que quedan disminuidas por el hecho de apelar a alguna clase de interés humano (por ejemplo, estético o sentimental). ${ }^{32}$ Los fines e intereses humanos son muy diversos, así como los medios para satisfacerlos. Por ejemplo, no es lo mismo talar un bosque por completo para 
enriquecerse rápidamente que entresacar los mejores árboles mientras se plantan otros nuevos. Tampoco se mide igual el valor instrumental que otorgamos al bosque como «almacén» de madera que el valor instrumental que le atribuimos como proveedor de paz espiritual, goce estético o sublimación mística. Y, por supuesto, el valor instrumental que se le atribuye en todos estos sentidos expuestos difiere de su valor instrumental como proveedor de un hábitat adecuado para ciertas especies animales, como ecosistema que absorbe gases nocivos o que evita la erosión del suelo, etc. Como vemos, hay una gran variedad de concepciones instrumentales del valor y gran parte de ellas son inconmensurables entre sí: no admiten una gradación cardinal, aunque de continuo nos veremos impelidos a establecer una ordenación jerárquica por las exigencias de satisfacción de nuestras necesidades y deseos.

Por tanto, ¿es realmente necesario, para estipular deberes ecológicos, que establezcamos un criterio de valor intrínseco que otorgue a la naturaleza valor como «fin en sí»? ¿No incurriremos con ello en un pleonasmo innecesario? Si de «apaciguar tensiones» se trata, hemos de articular criterios de valoración ecológica que prescindan de la noción de valor intrínseco. Hemos de considerar que, incluso cuando somos extremadamente respetuosos con la naturaleza por razones espirituales «profundas», estamos extrayendo alguna clase de utilidad y que ello no convierte nuestras acciones en moralmente «incorrectas». No importa que mis razones apelen a argumentos más o menos «instrumentalistas» o «intrínsecos»: lo que realmente importa es que las prescripciones morales de respeto hacia la naturaleza conduzcan a la protección adecuada de los derechos e intereses de las generaciones presentes y futuras de seres humanos que deberán conservar sus oportunidades de elección. ${ }^{33}$ Un principio semejante servirá para establecer un criterio jerárquico general que determine qué concepciones instrumentales del valor han de ser rechazadas. Para que una ética ecológica pueda responder con firmeza a la fe ciega en la prometeica posibilidad de sustitución o de creación de sucedáneos bastará en principio con prescribir deberes ecológicos desde la formulación originaria del imperativo kantiano y restringir la noción de valor intrínseco al ámbito humano. Dado que nos superponemos generacionalmente a través de los siglos, el imperativo no sólo ha de regir en el presente, sino indefinidamente hacia el futuro. Podemos afirmar que la naturaleza es sólo un medio para nuestros fines siempre que entre éstos tenga un lugar privilegiado mantener una relación de respeto hacia ella. Hay aquí un lugar de encuentro para las posiciones aristotélicas y kantianas que no tengo espacio para desarrollar convenientemente. Pero es evidente que los males más graves, como el calentamiento global o la desertización, no son sino atentados contra la humanidad, especialmente contra los derechos de los habitantes de los países más pobres y de nuestros descendientes. Una vez que se reconocieran derechos ambientales, semejantes males comenzarían a retroceder y de ello se beneficiaría indirectamente el mundo no humano.

No obstante, puede argumentarse que la extinción de ciertas especies, cuya utilidad para los seres humanos dista de estar clara, posiblemente no acarrearía el incumplimiento de deber moral alguno desde el punto de vista kantiano ni desde una concepción aristotélica de las virtudes ecológicas. Esta es una seria objeción que, sin embargo, podría contrarrestarse mediante un biocentrismo moderado que propone «cargar» la responsabilidad de la prueba sobre aquellos que promuevan 
la extinción de tales especies, los cuales se verían obligados a demostrar que no existen razones para preservarlas antes de proceder a su destrucción. Con ello, los organismos vivos, como pretenden los biocentristas, serían merecedores de consideración moral mientras no hubiera razones para convertirlos en medios para fines humanos (o de otros organismos). Pero obsérvese que, incluso en este caso, puede elaborarse un argumento que apela a intereses humanos para justificar la protección. Pensemos en organismos vivos que no aportan, aparentemente, bienestar alguno a los seres humanos, como podrían ser las cucarachas. Es complicado elaborar un argumento que demuestre el bienestar que nos procuran, pero no lo es más que afirmar su valor intrínseco o convertirlas en vida que debemos «reverenciar». A buen seguro, una minoría de entomólogos sentirán pasión por ellas y, probablemente, este es ya un argumento de peso para que no exterminemos la última cucaracha. Pero imaginemos que tales entomólogos señalaran indicios fiables de que las cucarachas y sólo ellas producen cierta sustancia que puede emplearse para curar una enfermedad grave. De pronto, el valor de las cucarachas para los seres humanos se eleva enormemente, hasta el punto de que exterminarlas significa atentar contra la humanidad. Pues bien, este es un argumento suficiente para no exterminar especie alguna: el exterminio de una especie es irreversible y con él perdemos para siempre el valor posible que tendría en el futuro para fines humanos. La incertidumbre ecológica, que recalca los límites de nuestra razón científica, aconseja adoptar un principio prudencial de conservación puesto que aún estamos descubriendo el alcance de nuestra relación con el mundo y cabe la posibilidad de que las generaciones futuras descubran el valor de las cucarachas. No deberíamos privarles de la oportunidad de hacerlo si valoramos a los seres humanos futuros como fines en sí. Con todo, se podrá replicar que los organismos individuales quedan desprotegidos, es decir, puedo matar cuantas cucarachas desee mientras esté seguro de que no están en peligro de extinción ni curan enfermedades. No obstante, creo que en casos como éste una teoría que afirme el valor intrínseco de las cucarachas no resultará más convincente para detener al exterminador que un argumento indirecto en la estela kantiana. Me temo que en casos como éste, si pretendemos proteger a las cucarachas, cualquier ética ecológica habrá de adoptar un tono emotivista más o menos explícito y prescindir de razones últimas. ${ }^{34}$

En definitiva, el «principio de reversión de la carga de la prueba» debería ser especialmente contemplado cuando esté en juego el bienestar y los derechos de seres humanos. Éstos han de concebirse progresivamente en un sentido más amplio, hasta abarcar derechos ambientales. ${ }^{35}$ Ello implicaría otorgar mayor significación moral a las necesidades de las generaciones futuras que a la satisfacción de nuestros deseos presentes, lo que se antoja como una tarea enormemente ardua pero ineludible. ${ }^{36}$ Con todo, las distintas concepciones del valor intrínseco podrán continuar disputando entre sí, aunque sea a riesgo de constituirse como «doctrinas comprehensivas» o de eludir problemas fundamentales; ello contribuirá, a buen seguro, a la sana «exacerbación de las tensiones filosóficas». Pues los fines humanos $-\mathrm{y}$ entre ellos el filosofar libre de trabashan de ser los primeros merecedores de respeto. 


\section{NOTAS}

1 Émile Cioran, «Adiós a la filosofía», en Adiós a la filosofía y otros textos, (prólogo y selección de Fernando Savater), Madrid, Alianza, pp. 129-130.

${ }^{2} \mathrm{El}$ uso de expresiones como «ética clásica» $\mathrm{O}$ «tradicional», «pensamiento convencional» 0 «cultura occidental» es muy frecuente en la literatura de la ética ecológica (sobre todo la ecocéntrica) para combatir el antropocentrismo. Bajo ellas suele incluirse el platonismo, la tradición judeocristiana y el racionalismo filosófico heredero de la Ilustración.

3 Tomo prestada la expresión «consideración moral» de Kenneth E. Goodpaster, 'On Being Morally Considerable', Journal of Philosophy, 75, 1978, pp. 308-325. Hay traducción castellana a cargo de Laura E. Manríquez: «Sobre lo que merece consideración moral», en Margarita Valdés (comp.), Naturaleza y valor. Una aproximación a la ética ambiental, México D.F., UNAM-FCE, 2004, pp. 147-168.

4 Véanse Aldo Leopold, 'The Land Ethic,'en Andrew Light and Holmes Rolston III (eds.), Environmental Ethics. An Anthology, Oxford, Blackwell, 2003, pp. 38-46 y Richard Sylvan (Routley), 'Is There a Need for a New, an Environmental, Ethic?', en ibid., pp. 47-52. Hay dos versiones en castellano del texto de Leopold: «La ética de la tierra», (traducción de Isabel Lucio-Villegas), en Aldo Leopold, Una ética de la tierra, (edición, introducción y notas de Jorge Riechmann), Madrid, Los Libros de la Catarata, 2000, pp. 133-156; y, con el mismo título, la traducción de Alicia Herrera Ibáñez en Margarita Valdés (comp.), op. cit., pp. 25-44.

5 Véase Robin Attfield, «El ámbito de la moralidad», en José M ${ }^{a}$ García Gómez-Heras, (coord.): Ética del medio ambiente: problema, perspectivas, historia, Madrid, Tecnos, 1997, pp. 71-88. La posición utilitarista clásica en defensa de los animales se remonta a Bentham, aunque encuentra formulación reciente en la obra de Peter Singer, Liberación animal, Madrid, Trotta, 1999.

${ }^{6}$ Kenneth Goodpaster, op. cit., p. 149. Véanse asimismo Paul W. Taylor, Respect for Nature. A Theory of Environmental Ethics, Princeton (Nva. Jersey), Princeton University Press, 1986; Robin Attfield, The Ethics of the Environmental Concern, Athens (Georgia), University of Georgia Press, 1983/1991 y Environmental Ethics. An Overview for the Twenty-First Century, Oxford, Polity, 2003.

7 Véase Holmes Rolston III, «Ética ambiental: valores en el mundo natural y deberes para con él», en Margarita Valdés (comp.), op. cit., pp. 69-98 (traducción de Laura E. Manríquez). Las teorías ecocéntricas más relevantes son la «Ética de la Tierra» de Aldo Leopold, John Baird Callicott o el propio Rolston y la deep ecology («ecología profunda») promovida por el filósofo noruego Arne Naess. Una muestra suficiente de sus posiciones la encontraremos en John Baird Callicott, In Defense of the Land Ethic: Essays in Environmental Philosophy, Albany, State University of NY Press, 1989; Bill Devall y George Sessions, Deep Ecology: Living as if Nature Mattered, Salt Lake City, Peregrine Smith Books, 1985; y Arne Naess, Ecology, Community, and Lifestyle, Cambridge, Cambridge Univ. Press, 1989. En la antología antes citada a cargo de Margarita Valdés se recoge la traducción de textos de estos autores.

8 Véanse John O'Neill, Ecology, Policy and Politics. Human Well-Being and the Natural World, Londres, Nva. York, Routledge, 1993, p. 9 y 'The Varieties of Intrinsic Value', en Andrew Light and Holmes Rolston III (eds.), op. cit., p. 132.

${ }^{9}$ Fritjof Capra, La trama de la vida. Una nueva perspectiva de los sistemas vivos, Barcelona, Anagrama, 1998, p. 29, subr. mío. En la 'deep ecology platform' se afirma el valor intrínseco del «florecimiento de la vida humana y no humana en la Tierra»; que «la riqueza y la diversidad de formas de vida son valores en sí mismos» y que «los humanos no tienen ningún derecho a reducir esa riqueza y diversidad, excepto para satisfacer necesidades vitales» (cf. Arne Naess, «La crisis del medio ambiente y el movimiento ecológico profundo», en Margarita Valdés, op. cit., pp. 220-221).

10 Véase John O'Neill, 'The Varieties of Intrinsic Value', cit., pp. 138-139.

11 Con ello se confunden las afirmaciones relativas a la fuente del valor con las relativas a su objeto. Véase ibid., p. 132.

12 Holmes Rolston III, op. cit., pp. 92 y 97. Cf. p. 82: «Una especie existe; la especie debe existir. La ética ambiental debe hacer estas aseveraciones y pasar cautelosamente de la biología a la ética»; $\mathrm{p}$. 84: «La unidad idónea de sobrevivencia (sic) es el nivel apropiado para la importancia moral»; y p. 90: «El desafío es encontrar un modelo claro de comunidad y descubrir una ética para él; una mejor biología para una ética mejor.»

13 Javier Muguerza, «De la materia a la razón», en Desde la perplejidad, Madrid, FCE, 1990 , p. 539. Véase asimismo «Filosofía y diálogo», en op. cit., p. 94 y La razón sin esperanza, Madrid, Taurus, 1986.

${ }^{14}$ Así reza la definición de valor intrínseco proporcionada por Robin Attfield en su Environmental 
Ethics, cit., p. 197: 'The kind of value that a thing has when it is valuable because of its very nature.'

15 Es importante subrayar que me refiero exclusivamente al valor moral. Por supuesto que otros seres «valoran», pero lo hacen en contextos muy diferentes. Aquí sólo nos interesa indagar qué sentido ético tiene la noción de valor intrínseco y su posible relación con la estipulación de deberes morales hacia la naturaleza.

16 Immanuel Kant, Fundamentación de la metafísica de las costumbres, Madrid, Espasa-Calpe, p. 104.

17 Immanuel Kant, «De los deberes para con los animales y los espíritus», en Lecciones de ética, Barcelona, Crítica, 2002, p. 287.

18 Ibid., p. 288.

19 Véase Tom Regan, «¿Se basa en un error la ética ambiental?», en Margarita Valdés, op. cit., pp. 119-146, esp. pp. 141-142. Regan distingue tres clases de teoría ética ecológica basadas en la noción de valor intrínseco. A saber: «teorías del valor intrínseco basadas en estados mentales», basadas en «estados de cosas» y basadas en «fines en sí mismos».

20 Ibid., p. 134.

21 Véase Robin Attfield, The Ethics of the Global Environment, Edimburgo, Edimburgh University Press, 1999, pp. 27-28.

22 La distinción entre «consideración moral» (moral considerability) y «significación» o «importancia moral» (moral significance) es establecida en Kenneth E. Goodpaster, op. cit., p. 151, para quien el «criterio de importancia moral [...] pretende regir los juicios comparativos de 'peso' moral en casos de conflicto».

23 Véase John Rawls, El liberalismo político, Barcelona, Crítica, 1993/2004, p. 43: «Una concepción es plenamente comprehensiva si abarca a todos los valores y virtudes reconocidos en un sistema articulado con precisión; mientras que una concepción es sólo parcialmente comprehensiva si se limita a abarcar un determinado número de valores y virtudes no políticos y está vagamente articulada. Muchas doctrinas religiosas y filosóficas aspiran a ser a la vez generales y comprehensivas.» A mi juicio, las perspectivas bio y ecocéntricas no pueden articularse de otro modo más que «comprehensivamente».

24 Cf. Robin Attfield, The Ethics of the Global Environment, cit., p. 39, trad. mía. Con anterioridad, Attfield sostenía una idea bastante similar del valor intrínseco (cf. The Ethics of Environmental Concern, cit., p. xvii).

25 De hecho, Attfield defiende una ética substantiva secular basada en la stewardship tradition -con raíces en la tradición judaica, cristiana e islámica- que contempla al ser humano como «albacea» o «fideicomisario» del planeta y que, a mi juicio, admite una lectura en clave antropocéntrica que propone una «instrumentalización responsable» de la naturaleza. Por otro lado, entre los méritos de Attfield hay que consignar que no aspira a revocar la «ética tradicional», como ilusoriamente pretenden los deep ecologists, y que mantiene el respeto del pluralismo axiológico que caracteriza el mundo contemporáneo como un punto central de su teoría.

26 No hay espacio aquí para tratar a fondo las cuestiones relativas a cómo una ética ecológica debe tratar de proporcionar criterios razonables para intervenir en los ecosistemas y definir el sufrimiento «gratuito». De hecho, biocentristas y ecocentristas disputan, a veces enconadamente, si deben tener prioridad los organismos individuales o la estabilidad ecosistémica en la gestión de los parques naturales. En esta clase de debates se advierte con gran claridad, a mi juicio, cómo el antropocentrismo ético es inevitable; pues en la decisión final tendrán sólo un peso limitado los criterios «objetivos» invocados por ambos. p. 107.

27 Javier Muguerza, «Filosofía y diálogo», cit.,

28 Véanse, respectivamente, la propuesta aristotélica de John O'Neill en Ecology, Policy and Politics, cit., así como las reformulaciones contractualistas de Andrew Dobson, en Justice and the Environment. Conceptions of Environmental Sustainability and Dimensions of Social Justice, Oxford, Oxford Univ. Press, 1998 y Brian Barry, en 'Sustainability and Intergenerational Justice', en Andrew Dobson (ed.), Fairness and Futurity. Essays on Environmental Sustainability and Social Justice, Oxford / Nva. York, Oxford Univ. Press, 1999, pp. 93-117.

29 John Rawls, Justicia como equidad. Una reformulación, Barcelona, Paidós, 2002, pp. 23-24.

30 Véase Bryan G. Norton, Toward Unity Among Environmentalists, Nueva York, Oxford University Press, 1991, esp. pp. 220-243.

31 Ibid., p. 235. Con todo, Norton no escapa a la cacofonía del valor intrínseco, pues denomina «intrinsic value» al «valor objetivo» y reserva el término «inherent value» para el «valor no instrumental». A su juicio, la diferencia entre ambos es epistemológica, no moral. El «valor intrínseco» (objetivo) es «anterior a la conceptualización humana, es descubierto», mientras que el «valor inherente» (no instrumental) es «postulado dentro de una teoría o cosmovisión humana» (trad. mía).

32 Esta es la sensación que produce el biocentrismo deontológico de Paul W. Taylor, quien da a entender que cualquier acción que no proceda de una «buena y pura voluntad» arraigada en la biocentric outlook, no es una acción «respetuosa» con la naturaleza. Véase Respect for Nature, cit. 
33 Véase Brian Barry, op. cit. y los artículos contenidos en la sección «La ecología y los límites del liberalismo» de la Revista Internacional de Filosofía Política, no 13, Madrid, julio 1999, pp. 11-117.

34 No analizo, por razones de espacio, casos más complicados, para los que probablemente un argumento basado exclusivamente en intereses humanos resulte insatisfactorio, como puede ser el sacrificio de toros de lidia. En este caso, los aficionados a las corridas de toros argumentarán que su bienestar depende del sacrificio de los animales, con lo que parecerá necesario apelar al valor intrínseco de la vida de los toros para defenderlos ante los intereses de aquéllos. Pero cuando el número de detractores sea lo suficientemente numeroso -por las razones últimas que sean- un argumento utilitarista, sumado al «principio de reversión de la carga de la prueba», bastaría para justificar su prohibición, puesto que el bienestar de la mayoría dependerá de que los toros dejen de sufrir.

35 Véase Tim Hayward, «Derechos constitucionales medioambientales y democracia liberal», en Revista Internacional de Filosofía Política, $\mathrm{n}^{\circ}$ 13, cit., pp. 65-82.

36 Un buen punto de partida es el orden de prioridades estipulado por Andrew Dobson, en Justice and the Environment, cit., p. 39. 